EXTENDED REPORT

\title{
Global core recommendations for a musculoskeletal undergraduate curriculum
}

\author{
A D Woolf, N E Walsh, K Åkesson
}

See end of article for authors' affiliations .....................

Correspondence to: Professor A D Woolf, Rheumatology Unit, Royal Cornwall Hospital, Truro TR1 3L, UK; anthony. woolf@rcht.cornwall. nhs.uk

Accepted 19 November 2003
Objective: To develop core recommendations for the learning outcomes of an undergraduate curriculum in musculoskeletal conditions for any parts of the globe.

Methods: Recommendations were developed by wide consultation with experts in orthopaedics, rheumatology, osteoporosis, and rehabilitation from all parts of the world who had interest and experience in these specialties, with the support of international and national societies. All possible knowledge, skills, and attitudes that might be of relevance to musculoskeletal conditions were initially considered and then reduced to those considered essential for all doctors.

Results: The recommendations focus on (a) basic skills to assess and diagnose musculoskeletal problems; (b) the competency to assess specific common or urgent musculoskeletal problems; (c) the theoretical background of the conditions and their management; and (d) the core knowledge necessary to support diagnosis and management, including basic sciences. At the end of the course, all students should be able to differentiate normal from abnormal locomotor symptoms in a patient, determine the relevant investigations and interpret the results, formulate a limited differential diagnosis, recognise the impact of the problem on the individual patient, and make an appropriate management plan.

Conclusions: The recommendations set global standards for the minimum level of competence in managing patients with musculoskeletal problems. They define what all doctors should know when graduating from medical school, regardless of further specialisation. They are intended to form the basis of a curriculum for a musculoskeletal course and can be adapted for any medical school in any country throughout the world.
M usculoskeletal conditions are common in society and consume enormous healthcare and social resources. They are the most common cause of severe long term pain and physical disability. With the exclusion of trauma, they represent almost $25 \%$ of the total cost of illness in westernised countries. ${ }^{1}$ They are the second most common reason for consulting a doctor, and in most countries constitute up to $10-20 \%$ of the primary care practice. ${ }^{2}$ They are the commonest cause of health problems limiting work in developed countries, and up to $60 \%$ of people on early retirement or long term sick leave claim a musculoskeletal problem as the reason. ${ }^{3}$ For simplicity, musculoskeletal problems may be grouped under the major headings: (a) joint conditions-for example, rheumatoid arthritis, osteoarthritis; (b) osteoporosis-for example, fragility fractures; (c) spinal disorders-for example, low back pain; (d) musculoskeletal injuries-for example, high energy limb fractures, strains and sprains often related to occupation or sports; and (e) childhood disorders. They include a spectrum of conditions, from those of acute onset and short duration to lifelong disorders. The impact of musculoskeletal conditions is predicted to increase dramatically in developing as well as developed countries with the aging of the population, changes in lifestyle resulting in obesity and lack of physical fitness, and the increase in road traffic accidents with the urbanisation and motorisation of the developing world. ${ }^{4}$ This great and increasing impact of musculoskeletal conditions is now recognised by the United Nations, the World Health Organisation, the World Bank, and governments throughout the world by their support of the Bone and Joint Decade 2000-2010 initiative. ${ }^{5}$

However, patients with musculoskeletal complaints are often ignored, their problems underestimated by doctors ${ }^{7}$ and, consequently, they do not have timely access to effective treatments. This reflects the common belief that we have to learn to live with musculoskeletal pain and disability as nothing can be done. It also reflects the inadequate education and training of doctors that begins at medical school.

Undergraduate education in musculoskeletal health is at present insufficient in most medical schools world wide in both basic science and clinical training. ${ }^{8}{ }^{9}$ Teaching is often mostly in orthopaedic and trauma clinics, giving the student little experience of the common problems that will be encountered in the community. Many students do not receive clinical rheumatology training in medical schools. ${ }^{10}$ In the examinations students are seldom assessed for their competency to take an appropriate history and to examine the musculoskeletal system. When they have been examined for basic competency, most have failed. ${ }^{11}$ The locomotor system is not examined as part of the general examination of a patient, ${ }^{12}{ }^{13}$ and residents in primary care programmes lack confidence in musculoskeletal problems. ${ }^{14}$ The lack of education in these conditions is similar in developing countries. Reducing disability is a WHO "Health for All" target, ${ }^{15}$ yet few interns are competent at assessing disability and handicap. ${ }^{16}$

There is therefore a clear need to improve the competencies of all doctors in the assessment and management of musculoskeletal conditions, and the education of medical students in these conditions in many medical schools needs to be reconsidered.

The aim of the initiative that is reported here is to produce graduates with the knowledge and skills to manage common or important musculoskeletal conditions from all medical schools, in all continents and cultures, irrespective of future specialty. To achieve this, the minimum level of competence in musculoskeletal conditions for all medical students, that is all future doctors, has been defined. Recommendations are 
made for the learning outcomes that should be obtained by all students. This provides medical school faculties with the priorities and educational areas that need to be considered when developing an undergraduate curriculum for a medical school in order to achieve these competencies. The recommendations give minimum standards for core knowledge and skills for musculoskeletal conditions that can be used as the basis for developing, implementing, and evaluating a curriculum.

The intention is to improve the quality of life for those with musculoskeletal conditions throughout the world by raising the quality of health care through education, thus meeting one of the goals of the Bone and Joint Decade. ${ }^{6}$ The recommendations are developed for global application by local adaptation. The recommendations represent the first global standards for a specific area of health.

\section{METHODS}

A consultative approach was used to develop recommendations for learning outcomes that reflect the educational needs of all doctors.

The recommendations have been developed through workshops and wide internet based consultation that was coordinated by the Bone and Joint Decade Education Task Force. The experts who participated in the focus group discussions and consultative process came from backgrounds of orthopaedics, rheumatology, rehabilitation, and osteoporosis and had interest and experience in education. They came from 29 countries from all parts of the world and formed the Bone and Joint Decade Undergraduate Curriculum Development Group (see "Acknowledgements"). The recommendations have been developed with the support of international and national societies for orthopaedics, rheumatology, and rehabilitation.

As an initial step, a structure for the recommendations was agreed. To be able to recommend which are the core competencies for all doctors, an inventory was initially made of all possible knowledge and skills that might be relevant in an undergraduate musculoskeletal course. In addition, the appropriate attitudes were considered. As a second step, each item was scrutinised by the experts during two workshops and the content reduced to include only those items that were considered by all to be essential competencies for all doctors. This prioritisation had to reflect the prevalence and impact of different conditions as well as the urgency to recognise or be aware of their possibility (red flags). The options allowed for defining the level of competency and ranged from knowledge, comprehension, application, analysis, and synthesis to the ability to evaluate. ${ }^{17}$ These proposals were then disseminated among all the experts for further comment until a consensus was reached. The final recommendations have been given the support of the major relevant organisations.

\section{RESULTS}

\section{Core recommendations for an undergraduate curriculum in musculoskeletal conditions}

It is recommended that the major emphasis of an undergraduate "Musculoskeletal course" should be on clinical skills and competencies relating to the musculoskeletal system. This must be supported by knowledge of the relevant basic science. Such a course must mirror the diversity and relative importance of the various musculoskeletal conditions in the different communities around the globe, from fracture to chronic degenerative disorders. In developing the proposals for the curriculum, we therefore structured the recommendations with these considerations in mind.

The initial focus of the recommendations (table 1) is on the basic skills necessary to assess and diagnose the person with a musculoskeletal problem, which is the ability to take an appropriate history and examine the musculoskeletal system to identify any relevant abnormalities. It is recommended that one method of assessing the musculoskeletal system should be taught irrespective of which specialty is teaching it. As this is a basic skill, it should be taught early in the curriculum along with the methods to assess other organ systems. Professional attitude should be included as an integral part of all teaching and professional development (fig 1).

The second level of the structure of these recommendations is the competency to assess specific problems of the musculoskeletal system (table 2) and this is related to prevalence and urgency of the specific conditions (fig 2). Emergencies may not be common, but it is essential for everyone to recognise them and to manage or refer as appropriate. It is recommended that the most common problems should receive greater emphasis in order to increase proficiency and confidence in managing them, and these may be adjusted according to local epidemiology. Examples are (a) the ability to assess someone with an upper limb injury: the student must have knowledge of the common upper limb fractures that may have been sustained, and be able to outline the immediate and long term management; or $(b)$ the ability to assess someone with hip joint pain, to recognise if it is due to osteoarthritis, and to be able to outline the principles of management.

The third level of the recommendations specifies the theoretical background knowledge required of the conditions and their management (table 3). Finally, the recommended knowledge that is required not only relates to the conditions encountered but also, importantly, considers the core knowledge necessary to support diagnosis and management (table 4). This includes basic knowledge of anatomy, physiology, cell biology, pathology as well as methods for appropriate management and treatment, including investigation.

It is recommended that basic competencies such as taking a screening history and performing a screening examination should be part of standard teaching of these skills for other systems. Clinical experience should be gained of all stages of the most prevalent conditions.

The ultimate goal of these recommendations is that at the end of such a musculoskeletal course all students should be able to assess, by appropriate history and examination, a patient with locomotor symptoms. They should be able to differentiate normal from abnormal structure and function, determine relevant investigations and interpret the results, formulate a limited differential diagnosis, recognise the impact of the problem on the individual patient and make

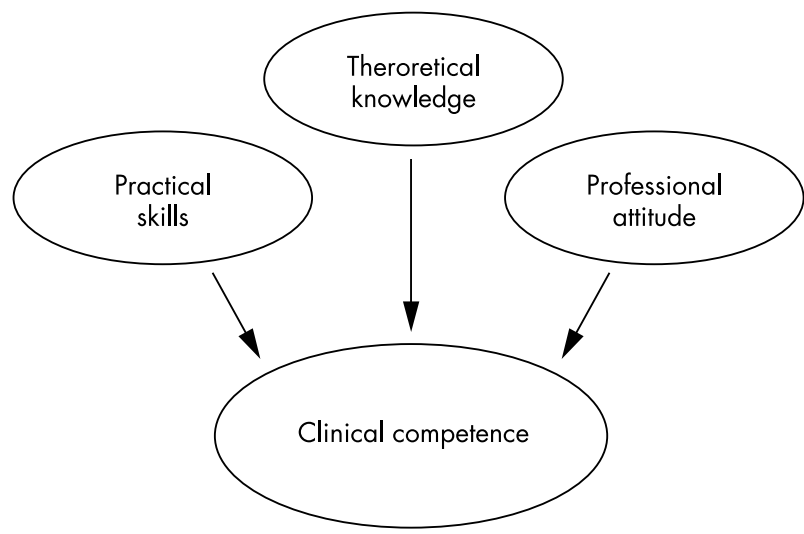

Figure 1 The underlying principle for developing competency in the musculoskeletal conditions. 
Table 1 Basic competencies in clinical assessment and diagnosis

\begin{tabular}{|c|c|}
\hline Category & Competencies required \\
\hline History & $\begin{array}{l}\text { To identify abnormality from normality (pain, displacement, dislocation stiffness, swelling, and limitation of activities) by a history } \\
\text { relevant to the musculoskeletal system } \\
\text { - To be able to apply a screening history as part of a general inquiry-for example, enquiring about pain, limitation of activities, } \\
\text { stiffness, and swelling ("PASS") } \\
\text { - To be able to take a relevant history in the knowledge of the characteristics of the major conditions of: } \\
\text { - Bone, including fracture, malignancy, infection, osteoporosis } \\
\text { - Joints, including rheumatoid arthritis, other arthritides, degenerative joint disease } \\
\text { - Connective tissue, including bursitis, tendonitis, tenosynovitis, enthesopathy } \\
\text { - Nerve tissue, including entrapment, peripheral neuropathy, radiculopathy } \\
\text { - Muscle tissue, including congenital, inflammatory, neurological } \\
\text { - To be able to take an appropriate history in relation to high energy and low energy trauma and injury and its sequelae } \\
\text { - To know how to assess acute and chronic pain according to its characteristics, severity, effects, and modulating factors } \\
\text { - To understand the impact on the individual of a chronic musculoskeletal condition due to impairment of function, limitation of } \\
\text { activities and restriction of participation (WHO ICF) }\end{array}$ \\
\hline Examination & $\begin{array}{l}\text { To identify normality and abnormality by examination of the musculoskeletal system } \\
\text { - To be able to perform a screening examination as part of general examination, for example by using the GALS (Gait, Arms, } \\
\text { Legs, and Spine) screen }{ }^{23} \\
\text { To be able to perform an appropriate examination on musculoskeletal trauma (inspection, palpation, range of motion and status } \\
\text { distal to the trauma) (colour, circulation, sensibility, mobility) } \\
\text { - To be able to perform an appropriate examination of major joints (hip, knee, humeroscapular) and small joints such as finger } \\
\text { joints in order to identify and characterise by examination, pain, tenderness, swelling, dislocation, displacement, deformity, } \\
\text { muscle wasting, weakness, abnormal movement, and functional impairment } \\
\text { - To be able to perform an appropriate examination of the neck, back, and sacroiliac joints }\end{array}$ \\
\hline $\begin{array}{l}\text { Attitude and } \\
\text { communication skills }\end{array}$ & $\begin{array}{l}\text { To demonstrate the appropriate attitude and communication skills for the management of people with acute and chronic } \\
\text { musculoskeletal conditions } \\
\text { - To have an understanding of the problems of people with musculoskeletal conditions and the full impact on the individual and } \\
\text { their care givers (for example, focus on chronic low back pain) } \\
\text { - To have a holistic approach to the patient }\end{array}$ \\
\hline
\end{tabular}

an appropriate management plan (medical, surgical, rehabilitation). They should also know how common the various conditions are in their own society.

\section{Use of the core recommendations: local adaptation}

The recommendations have been developed to be relevant to all parts of the globe. They will enable a curriculum to be developed from them that is locally applicable. A curriculum that is developed from these recommendations should meet any national guidelines and must be adapted to reflect local needs, priorities, and opportunities. Priorities within the curriculum should be based on the local prevalence, severity, and urgency of the condition or the clinical problem and the relevance to the geographic and socioeconomic situation.

\section{DISCUSSION}

Core recommendations for a musculoskeletal undergraduate curriculum have been developed for application in any

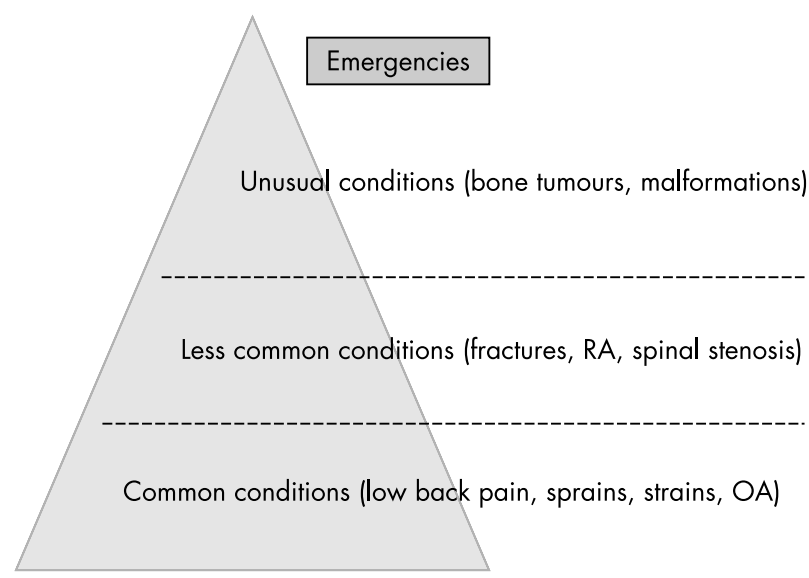

Figure 2 The structural levels related to prevalence and urgency used when developing the recommendations. country and culture. These recommendations represent the first global standards for a specific area of health. They will serve as quality assurance credentials for doctors wherever they are based and as ways of ensuring adequate educational grounding for migrating doctors, ${ }^{18}$ but most importantly as a mechanism of quality improvement of medical education to meet health needs in all countries and cultures. By focusing on learning outcomes, these recommendations can take into account the variations among countries in medical education due to differences in teaching tradition, culture, socioeconomic conditions, the health and disease spectrum, and different forms of healthcare delivery systems. ${ }^{18}$

Recommendations have been made to improve the competency of all doctors in the assessment and management of musculoskeletal conditions. The recommendations relate to all aspects of bone and joint health and disease on a background of basic knowledge in anatomy, physiology, and cell biology, in addition to clinically relevant adjacent areas such as neurology and traumatology. In addition, a holistic approach to clinical care is essential that brings together, for example, primary care, medical, surgical and rehabilitation skills, and other relevant health professionals working as a team. The implementation of these recommendations is therefore well suited to the trend to integrate courses both vertically and horizontally.

The main focus of these recommendations is on clinical competencies. The teaching of general history and examination skills should consider the recommendations for a screening history and examination of the musculoskeletal system. The course will, for the most part, come at the stage of clinical training, commonly during the third or fourth year of training. Even if structure and pathophysiology of the musculoskeletal system are taught at an earlier stage, reference to such knowledge and clinical context lies within the framework of a clinical musculoskeletal course.

Defining the essential content of a course is a challenging task, as experts tend to overestimate the importance of their own field or area of interest. Furthermore, the increase in 
Table 2 The assessment of specific problems (specifically related to urgency, importance, and/or prevalence)

\begin{tabular}{ll}
\hline Problem & Action required \\
\hline Emergencies/red flags & To know when to immediately refer a patient with a condition that requires urgent specialist management. This requires the ability \\
to identify, characterise, and differentiate through patient inquiry, examination, and limited investigation, within the context of \\
knowledge and outline management of: \\
- Open fractures \\
- Fractures with nerve or vascular compromise \\
- Cauda equina compression \\
- Joint infection \\
- Soft tissue infection \\
- Bone infection \\
- Temporal arteritis
\end{tabular}

Extremity problems:

traumatic

Extremity problems: nontraumatic

Spinal problems approach

To identify, characterise, and differentiate through patient inquiry, examination and limited investigation, within the context of knowledge. This requires the ability to:

- Take a relevant history in the knowledge of the characteristics of trauma and fracture

- Identify and characterise, for example, injuries that include fracture of long bones, fracture involving joints, joint dislocations, sprains, and strains

- Evaluate the energy of the trauma and its impact on type of injury (low energy trauma and fragility fracture, traffic accident and complicated fractures)

To identify, characterise, and differentiate through patient inquiry, examination, and limited investigation, within the context of knowledge. This requires the ability to:

- Take a relevant history in the knowledge of the characteristics of major, non-traumatic extremity problems - Joint disorders (osteoarthritis, rheumatoid arthritis)

- Soft tissue disorders (bursitis, tendonitis, tenosynovitis, enthesopathy, and nerve entrapment)

- Muscle disorders (congenital, inflammatory, and neurological)

- Bone conditions (malignancy and infection)

- Identify and characterise, for example, conditions that include:

- Joint inflammation and/or damage such as osteoarthritis, rheumatoid arthritis

- Soft tissue conditions such as bursitis, tendonitis, tenosynovitis, enthesopathy, and nerve entrapment

- Muscle conditions such as congenital, inflammatory and neurological

- Bone conditions such as malignancy and infection.

This requires the ability to:

- Take a relevant history in the knowledge of the characteristics of the major conditions:

- Mechanical neck/back pain (for example, non-specific low back pain, lumbago)

- Spinal cord or root entrapment (for example, herniated lumbar disc)

- Vertebral fracture of traumatic origin

- Vertebral fracture of osteoporotic origin

- Inflammatory back pain (for example, ankylosing spondylitis)

- Spinal deformity (for example, scoliosis)

- Destructive (infectious and tumour related) back pain (for example, tuberculosis, metastasis, certain cancers)

Problem based symptomatic To construct an appropriate differential diagnosis and plan of patient inquiry, examination, limited investigation, and assessment for a patient presenting with:

- Musculoskeletal injury

- Joint pain-poly-, mono-, and periarticular

- Back pain

- Regional pain or stiffness

- Generalised pain or stiffness

- Decrease or loss of motion or weakness

- Altered sensation

- Deformity

- Mass

This should relate to mechanisms of conditions (also considered later in the context of knowledge):

- Traumatic (for example, low energy as in osteoporosis, occupational injuries, or sports injuries)

- Vascular/ischaemic (for example, compression or disruption of a vessel)

- Neurological (for example, compression)

- Infectious (for example, joint or bone)

- Degenerative (for example joint or spine)

- Autoimmune or immune mediated (for example, rheumatoid arthritis)

- Metabolic/toxic (for example, osteoporosis, gout)

- Inherited/developmental/congenital (for example, scoliosis)

- Neoplastic (for example, myeloma)

- Psychological (for example chronic pain syndromes, fibromyalgia)

scientific knowledge is tremendous over the past decades and competence in musculoskeletal conditions is competing with new areas demanding time in a programme. One of our duties is therefore to help to delineate the border between core competence when leaving a medical school and competence that should be deferred to postgraduate training. A consideration is that problems such as chronic disease and pain management, disability, rehabilitation, and community needs are recognised as core to undergraduate education, ${ }^{19}$ and musculoskeletal conditions can provide ideal experiences of these situations.

We have carefully reviewed all areas of potential content and, through this process, tried to define the level of skill or knowledge that all doctors should have as well as excluding content which is beyond this-that is, suitable for postgraduate or fellowship training. Notwithstanding this, the 
Table 3 The knowledge of main characteristics and the principles of management and rehabilitation of common musculoskeletal conditions (the theoretical background)

\begin{tabular}{|c|c|}
\hline Characteristics & Ability required \\
\hline \multirow[t]{2}{*}{ Fracture/injury/trauma } & $\begin{array}{l}\text { In theoretical terms, have the ability to: } \\
\text { - Specify the symptoms, signs, and immediate complications } \\
\text { - Outline the assessment and appropriate investigation } \\
\text { - Outline the immediate and long term management of patient with: } \\
\text { - Common adult fractures } \\
\text { - Joint dislocation } \\
\text { - Soft tissue injuries } \\
\text { - Acute spinal injury } \\
\text { - Multiply injured patient } \\
\text { - Joint instability (for example, knee, finger) }\end{array}$ \\
\hline & $\begin{array}{l}\text { Clinical experience should be gained of all stages of injury and healing (for example, from emergency room to } \\
\text { rehabilitation clinic). }\end{array}$ \\
\hline $\begin{array}{l}\text { Joint and soft tissue } \\
\text { conditions }\end{array}$ & $\begin{array}{l}\text { In theoretical terms, have the ability to: } \\
\text { - Specify the symptoms, signs and predisposing factors } \\
\text { - Outline the assessment and appropriate investigation } \\
\text { - Propose a limited differential diagnosis and } \\
\text { - Outline the principles of management of a patient with } \\
\text { - Osteoarthritis } \\
\text { - Chronic inflammatory arthritis - for example, rheumatoid arthritis, spondyloarthropathy (optional) } \\
\text { - Soft tissue lesion/enthesopathy-for example, rotator cuff lesion and/or tennis elbow (other soft tissue lesions } \\
\text { - optional) } \\
\text { - Fibromyalgia/chronic generalised pain } \\
\text { - Rheumatic fever } \\
\text { - Autoimmune connective tissue diseases-for example, SLE } \\
\text { - Viral arthritis( including HIV) } \\
\text { - Polymyalgia rheumatica (optional) }\end{array}$ \\
\hline Spine & $\begin{array}{l}\text { In theoretical terms, have the ability to: } \\
\text { - Specify the symptoms and signs } \\
\text { - Outline the assessment and appropriate investigation } \\
\text { - Propose a limited differential diagnosis } \\
\text { - Lutline the principles of management of a patient with } \\
\text { Lack pain and sciatica }\end{array}$ \\
\hline Tumours & $\begin{array}{l}\text { In theoretical terms, have the ability to: } \\
\text { - Specify the symptoms, signs and predisposing factors } \\
\text { - Outline the assessment and appropriate investigation } \\
\text { - Outline the principles of management of a patient with: } \\
\text { - Metastatic bone disease } \\
\text { - Primary bone and soft tissue tumours (optional) }\end{array}$ \\
\hline Bone disorder & $\begin{array}{l}\text { In theoretical terms, have the ability to: } \\
\text { - Specify the symptoms, signs, and predisposing factors } \\
\text { - Outline the assessment and appropriate investigation } \\
\text { - Propose a limited differential diagnosis } \\
\text { - Outline the principles of management of a patient with: } \\
\text { - Osteoporosis } \\
\text { - Pageomalacia }\end{array}$ \\
\hline Paediatric & $\begin{array}{l}\text { In theoretical terms, have the ability to: } \\
\text { - Outline the clinical features and } \\
\text { - Outline the principles of management of paediatric locomotor conditions including: } \\
\text { - Common paediatric fractures (wrist/forearm, elbow, femoral shaft) } \\
\text { - Paediatric musculoskeletal infections } \\
\text { - Paediatric hip conditions - for example, developmental dislocation of hip } \\
\text { - Juvenile chronic/idiopathic arthritis } \\
\text { - Chronic paediatric conditions that offen require orthopaedic management (club foot, scoliosis, neuromuscular } \\
\text { disorders) (optional) }\end{array}$ \\
\hline Related knowledge & $\begin{array}{l}\text { To outline the relative prevalence, health, and economic impact, major associations, and expected prognosis/outcome of } \\
\text { specific musculoskeletal conditions } \\
\text { - Fracture-low and high energy } \\
\text { - Cow back pain } \\
\text { - Osteoorthrittis - hip and knee } \\
\text { - Rheumatoid arthritis }\end{array}$ \\
\hline
\end{tabular}

recommendations need to be tailored to each geographic and socioeconomic area and include the aspects of local prevalence of conditions.

Competency is essential in history and examination and similar approaches are recommended for primary care, rheumatological, orthopaedic, or rehabilitation assessment. It is also essential to be able to recognise and act upon musculoskeletal emergencies. Only conditions that are common or teach general principles have been included and a systematic approach taken as much as 
Table 4 The core knowledge to support diagnosis and management
(A) Basic knowledge
To identify the bones and joints within the articulated human skeleton
To specify the major muscle groups, their function, and their root innervation
To specify major vessels and nerves related to the musculoskeletal problems

To outline the basic physiology, cell biology, and pathology relating to musculoskeletal conditions

- This includes aging, injury and disease states, and repair of musculoskeletal tissues (bone, cartilage, synovium, muscle, entheses). (Including mechanical, traumatic, metabolic, vascular, degenerative, inflammatory, and immune mediated conditions, neoplastic, inherited, and developmental)

\section{(B) Knowledge of methods for management and treatment}

Management strategies To be able to describe the strategies available for the management, including rehabilitation, of acute and chronic musculoskeletal disorders (listed above), and for chronic musculoskeletal pain.

- This includes education, drug treatment, physical treatments, relaxation, self efficacy, psychosocial interventions, social support, referral, and shared care

- To be familiar with factors that influence adherence to a management plan.

Pharmacology

To know the major indications, adverse effects, drug interactions, and contraindications of drugs commonly used in the management of musculoskeletal conditions

- Acute and chronic pain management

- Disease modifying treatment

This includes analgesics, non-steroidal anti-inflammatory drugs, antidepressant drugs in pain management, corticosteroids, hypouricaemic drugs, disease modifying and cytotoxic drugs, treatment for osteoporosis

There should be familiarity with the placebo effect and an awareness of special situations with these drugs, such as pregnancy

Non-surgical treatment To be able to describe the principles of reduction, fixation, and immobilisation for fracture and multiple trauma management

for trauma

- To know the most common non-operative procedures for fracture and dislocation. This includes closed reduction, the use of external fixation devices such as Plaster of Paris or elastic wraps. Common injuries may include fracture of the wrist or proximal humerus, shoulder dislocation, and ankle sprain

Surgical treatment To be able to describe the surgical principles of reduction, fixation, and immobilisation for fracture and multiple trauma management

- This includes familiarity with the treatment of the most common fractures such as hip, wrist, and ankle fractures

- To know the most common operative procedures for fracture and dislocation. This includes open reduction, the use of internal and external fixation devices

To know the most common operations for musculoskeletal conditions.

- Arthroscopy of the knee,

- Arthroplasty of hip and/or knee

- Back surgery (discectomy, spinal fusion)

- Amputation, synovectomy, osteotomy, arthrodesis, and carpal tunnel decompression

To be able to describe the benefits and complications of large joint (hip, knee) replacement surgery This includes the complications of DVT, infection and loosening, and expected durability of implant

Other procedures

To know the indications, benefits and risks of:

- Joint aspiration

- Injections of joint, soft tissue and spine

Rehabilitation To know the benefits of rehabilitation of musculoskeletal conditions and their effect on outcome of treatment process and total patient function

- This should be in the context of different musculoskeletal conditions such as amputations, spinal cord injury, trauma, fractures, osteoporosis, osteoarthritis, rheumatoid arthritis, mechanical soft tissue lesions, neck and back pain, disuse atrophy, and deconditioning due to prolonged immobilisation

- Rehabilitative interventions should include physiotherapy and occupational therapy

- The different problems of lower versus upper limb amputation should be understood

To know the common orthoses, limb prostheses, and adaptive equipment for individual patients with a musculoskeletal impairment

- For example, when to use Plaster of Paris, sticks, cane, walker, corset, activities of daily living equipment

Prevention

To know prevention strategies for common musculoskeletal conditions

- Specific examples might include trauma, fractures, osteoporosis, osteoarthritis, osteoarticular infection, mechanical soff tissue lesions, and neck or back pain

- Strategies include benefits and risks of lifestyle factors, physical activity, minimising immobility, and avoidance of specific risks for musculoskeletal conditions

(C) Knowledge of methods to assist diagnosis and management

Laboratory assessment To demonstrate an appropriate use and interpretation of laboratory investigations for diagnosis and assessment of musculoskeletal conditions

- Full blood count (haemoglobin/white cells)

- Acute phase response

- Erythrocyte sedimentation rate (ESR)

- C reactive protein (CRP)

- Immunological investigations

- Rheumatoid factor

- ANA

- Serum biochemistry, including calcium, alkaline phosphatase, creatine kinase, and albumen

- Synovial fluid analysis (white cells, glucose, culture, crystals)

Imaging

To demonstrate the appropriate use of imaging for the diagnosis and assessment of musculoskeletal conditions and to be able to interpret reports

- for example, $x$ ray, CT scan, MRI, bone densitometry, bone scintigraphy, musculoskeletal ultrasound 
possible, because there is little value in a comprehensive but unrealistic set of recommendations. The level of competency has also been carefully set to be appropriate for all doctors.

The approach used to develop the recommendations has relied on a wide consultative process, which is clearly a strength. Professionals from all disciplines have participated in the process, a necessity when dealing with conditions that more than most benefit from multiprofessional care. Furthermore, medical teachers from all parts of the world have had an input, many with a broad knowledge of educational needs within their region, which increases the emphasis on core versus specialist knowledge and allows for a global perspective. Drawbacks of our approach may still be the difficulty of securing the involvement of all stakeholders and thereby their opinions. In reality, selection of participants is inevitable and it is virtually impossible to ensure true representation. However, we believe that through inclusion of representatives from all specialties and with support from major organisations the recommendations are widely acceptable.

The recommendations are given as learning outcomes. The elements of content, teaching, and learning strategies, assessment processes, and evaluation processe ${ }^{20}$ need to be developed locally. The structure and time allocation within a curriculum will depend on the degree of integration, vertical and horizontal. From knowledge of medical schools that have a comprehensive curriculum for musculoskeletal conditions, it is estimated that a minimum of between 4 and 6 weeks is necessary to cover the clinical curriculum, with basic nonclinical background given at previous stages of the undergraduate course. However, the aim should be a 6-12 week clinical course in order to provide a more in depth proficiency. Although this is far greater than in most medical schools, it would more appropriately reflect the impact of musculoskeletal conditions on individual subjects, healthcare systems, and society.

It is not within the framework of this document to recommend preferred methods of teaching, while naturally the skills of the teachers should be appropriate to the curriculum. The competencies relate to a wide spectrum of expertise, including orthopaedics, traumatology, rehabilitation, rheumatology, other health professions related to musculoskeletal conditions, and also to primary care. Teaching and training should preferably be integrated, multidisciplinary, and ensure a consistent approach to the learning objectives. The trend towards providing education in a variety of environments, including hospitals, general practices, and community medical services, is also most appropriate to these conditions.

Assessment of competency should relate to the learning objectives of any curriculum that is based on these recommendations. Practical assessments such as objective structured clinical examinations are in particular suitable because many of the learning objectives relate to skills. It is also important to ensure that appropriate attitudes have been developed.

The undergraduate programme provides the foundation for postgraduate training. If management of musculoskeletal conditions is omitted or insufficient, the first stepping-stone for continued professional training will be missing. This is particularly important for those going into primary care or family practice as most patients with musculoskeletal complaints will be assessed and treated within primary care settings. A next step in the area of musculoskeletal education and training is therefore to define measures to improve outcome of care from postgraduate and specialist training, based on the commonality of these conditions. ${ }^{21}$

\section{CONCLUSION}

In conclusion, it is essential that a musculoskeletal undergraduate curriculum be implemented in medical student instruction world wide that reflects the burden of musculoskeletal disease. The aim of these core recommendations is to facilitate this by setting standards for the minimum level of competence for all doctors in managing patients with musculoskeletal problems, from trauma to chronic conditions. They are intended to form the basis when developing a curriculum in musculoskeletal conditions that can be adapted for any medical school in any country. They provide a framework for any medical school faculty, administrator, or curriculum committee to expand the knowledge base for future physicians so that they will be able to provide better and appropriate care for their patients.

\section{ACKNOWLEDGEMENTS}

The Bone and Joint Decade (BJD) Undergraduate Curriculum Development Group are experts from different specialties, organisations, and countries with expertise in medical education.

The participants were G Abelseth (Canada), D Barroclough (Australia), P Cantista (Portugal), J Dequeker (Belgium), M Doherty (UK), K Dreinhoefer (Germany), T El-Hadidi (Egypt), R Handa (India), J Homik (Canada), K Joughin (Canada), G Mody (South Africa), R Rizzoli (Switzerland), S Scherl (USA), J A P da Silva (Portugal), M Speeckhaert (Belgium), O Svenson (Sweden), and members of the EULAR Standing Committee for Education and Training.

Organisations that have been involved in the consultative process include International League of Associations for Rheumatology (ILAR), International Society of Orthopaedic Surgery and Traumatology (SICOT), International Society of Physical and Rehabilitation Medicine, International Osteoporosis Foundation (IOF), European Federation of National Associations of Orthopaedics and Traumatology (EFORT), European League Against Rheumatism (EULAR), European Board of Rheumatology, European Union Of Medical Specialists (UEMS) Sections of Rheumatology, Rehabilitation, and of Orthopaedics, European Board of Orthopaedics and Traumatology, Asia Pacific League of Associations for Rheumatology (APLAR), Pan American League of Associations for Rheumatology (PANLAR), African League of Associations for Rheumatology (AFLAR), American Academy of Orthopedic Surgeons, American College of Rheumatology, American Academy of Physical Medicine and Rehabilitation, American Board of Physical Medicine and Rehabilitation, Association of Academic Physiatrists.

We thank ILAR and the EULAR Standing Committee for Education for supporting the workshops. These workshops were supported financially, in part, by Merck and Pharmacia Corporation.

\section{Authors' affiliations}

A D Woolf, Institute of Health and Social Care, Peninsula Medical School, Rheumatology Unit, Royal Cornwall Hospital, Truro TR1 3L, UK N E Walsh, Department of Rehabilitation Medicine, University of Texas Health Science Center, San Antonio, Texas, 78229-3900, USA

K Åkesson, Lund University, Department of Orthopaedics, Malmö University Hospital, SE-205 02, Malmö, Sweden

\section{REFERENCES}

1 Jacobson L, Lindgren B. Vad kostar sjukdomarna? (What are the costs of illness?). Stockholm: Socialstyrelsen (National Board of Health and Welfare), 1996.

2 Rasker JJ. Rheumatology in general practice. Br J Rheumatol 1995;34:494-7

3 NBHW. Year Book of Health and Medical Care. Stockholm: Socialstyrelsen (National Board of Health and Welfare), 2001. Available at URL: http:// www.sos.se/sosmenye.htm (accessed 25 February 2004).

4 Woolf AD, Åkesson K. Understanding the burden of musculoskeletal conditions. The burden is huge and not reflected in national health priorities. BMJ 2001;322:1079-80.

5 Heinegard D, Johnell O, Lidgren L, Nilsson O, Rydevik B, Wollheim F, et al. The Bone and Joint Decade 2000-2010. Acta Orthop Scand 1998;69:219-20.

6 Woolf AD. The Bone and Joint Decade 2000-2010. Ann Rheum Dis 2000;59:81-2.

7 Woolf AD, Zeidler H, Haglund U, Carr AJ, Chaussade S, Cucinotta D, et al. Musculoskeletal pain in Europe: its impact and a comparison of population 
and medical perceptions of treatment in eight European countries. Ann Rheum Dis 2004;63:342-7.

8 Pinney SJ, Regan WD. Educating medical students about musculoskeletal problems. Are community needs reflected in the curricula of Canadian medical schools? J Bone Joint Surg Am 2001;83:1317-20.

9 Williams JR. The teaching of trauma and orthopaedic surgery to the undergraduate in the United Kingdom. J Bone Joint Surg Br 2000;82:627-8.

10 Kay LJ, Deighton CM, Walker DJ, Hay EM. Undergraduate rheumatology teaching in the UK: a survey of current practice and changes since 1990. Arthritis Research Campaign Undergraduate Working Party of the ARC Education Sub-committee. Rheumatology (Oxford) 2000;39:800-3.

11 Freedman KB, Bernstein J. The adequacy of medical school education in musculoskeletal medicine. J Bone Joint Surg Am 1998:80:1421-7.

12 Ahern MJ, Soden M, Schultz D, Clark M. The musculo-skeletal examination: a neglected clinical skill. Aust NZ J Med 1991;21:303-6.

13 Doherty M, Abawi J, Pattrick M. Audit of medical inpatient examination: a cry from the joint. J R Coll Physicians Lond 1990;24:115-18.

14 Clawson DK, Jackson DW, Ostergaard DJ. It's past time to reform the musculoskeletal curriculum. Acad Med $2001 ; 76: 709-10$.

15 World Health Organisation/Europe. Health $21-$ The health for all policy for the WHO European Region-21 targets for the 21 st century. WHO Regional Office for Europe, 1998
16 Crotty M, Ahern MJ, McFarlane AC, Brooks PM. Clinical rheumatology training of Australian medical students. A national survey of 1991 graduates. Med J Aust 1993;158:119-20.

17 Bloom BS. Taxonomy of educational objectives: the classification of educational goals: Handbook I, cognitive domain. New York; Toronto: Longmans, Green, 1956.

18 WFME Global Standards for Quality Improvement-Basic Medical Education. WFME, 2003. Available at: http://www.wfme.org (accessed 25 February 2004).

19 Tomorrow's doctors. Recommendations on undergraduate medical education. London: General Medical Council, 2002.

20 Prideaux $D$. ABC of learning and teaching in medicine. Curriculum design. BMJ 2003;326:268-70.

21 Åkesson K, Dreinhoefer K, Woolf AD. Improved education in musculoskeletal conditions is necessary for all doctors. Bull World Health Org 2003;81:677-83.

22 WHO International Classification of Functioning, Disability and Health. Available at: http://www3.who.int/icf/icftemplate.cfm laccessed 24 February 2004).

23 Doherty M, Dacre J, Dieppe P, Smith M. The "GALS" locomotor screen. Ann Rheum Dis 1992;51:1165-9.

\section{Get published within days of acceptance with} ARD

We are delighted to announce that the Annals of the Rheumatic Diseases launched a "publish ahead of print" programme in February 2004. Selected papers are fast tracked and published online months before they appear in the print journal.

Papers of major significance to the international rheumatology community are published within days of acceptance. The first published article is the raw accepted manuscript; edited and typeset versions are also published as soon as they are available.

In addition to being available on ARD Online, the publish ahead of print articles are searchable through PubMed/ Medline-establishing primacy for your work. They are linked from the ARD Online home page.

$A R D$ 's publish ahead of print programme is unique among the major rheumatology journals - to take advantage of this service submit your papers to Annals of the Rheumatic Diseases using our online submission and review system Bench>Press (http://submit-ard. bmijournals.com). For further information contact ARD@bmigroup.com. 